\title{
FRAGMENTOS PARA ARMAR. INDICIOS SOBRE LA PRESENCIA ARTIGUISTA EN BUENOS AIRES
}

POR

\author{
FABIÁN HERRERO
}

Conicet. Instituto Ravignani. Universidad de Buenos Aires

Este estudio presenta indicios sobre la presencia de agentes artiguistas operando en la escena politica de Buenos Aires durante el decenio de 1810. A partir de los documentos que ofrece el Archivo Artigas, los órganos de prensa local y diferentes legajos de gobierno del Archivo General de la Nación, es posible rastrear algunas de sus actividades y reconocer algunos de sus planes políticos. Toda esta evidencia pone en duda la imagen fuerte de la historiografia federal que considera que en esta provincia no se presentan ideas de ese signo durante los primeros años revolucionarios.

Palabras clave: Federalismo, artiguismo, politica, revolución, Buenos Aires.

En la ciudad de Buenos Aires, durante los primeros años de la Revolución de Mayo, he detectado la intervención de varios actores que adhieren al llamado artiguismo. Hacia 1815, como se sabe, este tipo de iniciativa tuvo cierto impacto en diversas provincias (como Santa Fe o Córdoba), las cuales formaron una coalición cuya cabeza visible es justamente José Artigas. Sin embargo, los historiadores del periodo no han advertido que, unos años antes, es posible señalar una presencia pública similar en territorio porteño. En las páginas que siguen, analizo, particularmente, una parte de mi investigación sobre esas huellas del federalismo oriental, las cuales forman parte de un trabajo mayor sobre el federalismo bonaerense entre los años 1810 y $1820^{1}$.

Mi objetivo central es examinar algunos indicios sobre la presencia de uno de los actores estudiados, Felipe Santiago Cardoso, y, sobre todo, describir y determinar qué ideas federalistas expone. Para una mejor comprensión del

1 Herrero, 2008. 
tema, conviene indicar previamente algunos problemas de la cultura política. ¿Qué ocurre con el nuevo poder local luego del derrumbe de la monarquía española? ¿Por qué los especialistas hablan de la importancia política de varios conceptos como soberanía del pueblo y de los pueblos, centralismo y federalismo? Y en este último caso, ¿qué diferencias existen entre las dos principales variantes de ese signo, esto es, confederación y estado federal?

\section{UnA NUEVA LEGITIMIDAD: SoberANía DEL PUEBLO O DE LOS PUEBLOS, CENTRALISMO Y FEDERALISMO}

Las revoluciones de independencia rompen con el modelo político de la monarquía española. Esa ruptura, a decir verdad, no se da de cualquier manera. Una de las primeras medidas que adoptan las ciudades americanas es transitar por una especie de camino intermedio, debido a que rápidamente afirman «un estatuto de autonomía en el marco de la monarquía castellana». Siguiendo ese sendero, como lo ha puesto de relieve José Carlos Chiaramonte, aparece de inmediato la alternativa que dividirá profundamente a las fuerzas políticas y de hecho configurará el cauce fundamental de la cultura política del periodo. Por un lado, quienes entendían que las decisiones a tomar debían partir del conjunto de los pueblos soberanos, los que en términos del Derecho de Gentes eran personas morales en condiciones de igualdad, independientemente de su poderío y tamaño, y sin cuyo consentimiento, según el mismo Derecho, ninguna decisión que les concerniera poseía legitimidad. Y, por otro lado, quienes consideraban necesario organizar de inmediato un nuevo Estado, a cuya cabeza debía figurar la antigua capital del reino, en ese caso Buenos Aires, y frente a la cual los demás pueblos eran subordinados ${ }^{2}$.

Es de este modo que una de las cuestiones claves que se plantearon por esos agitados años es la legitimidad del nuevo poder. Se trata, en rigor, de pensar y de discutir cómo reemplazar la legitimidad de la monarquía castellana por otra soberanía igualmente legítima, la cual obviamente debería garantizar el orden social. Dentro de este marco, debe entenderse porque durante el periodo de 1810-1820 ocupa un lugar central el complejo entrelazamiento de dos grandes conflictos: el que opone, como ya señalamos, a los «pueblos» del territorio del ex Virreinato con la antigua capital del reino, Buenos Aires - conflicto entre las tendencias autonómicas y las centralizadoras ${ }^{3}$. Para decirlo con otras palabras, dos tendencias chocan inexorablemente en la arena pública: la

2 Chiaramonte, 1997: 128. Golman, 2008: 9-18. Verdo, 2002, 2006.

3 Chiaramonte, 1997: 134-135. 
centralista como sinónimo de una sola soberanía nacional y la del federalismo como sinónimo de varias soberanías.

Ahora bien, ¿Qué se entiende por el vocablo federal? La voz federalismo responde a significados diferentes. Por este motivo resulta conveniente tener presente qué entendemos tanto por estado federal como por confederación. Comienzo por este último.

En el lenguaje político el término confederación tiene dos significados ${ }^{4}$ : uno genérico y otro específico. Podría decirse que en la acepción genérica es aproximadamente sinónimo de asociación. Entidades deportivas, comerciales, educativas o gremiales, suelen organizarse de ese modo. Es lo que sucede por ejemplo en el caso sindical, en donde las distintas organizaciones del país se han agrupado en lo que se denomina Confederación General del Trabajo. En la acepción específica, de la que me ocupo aquí, el vocablo designa en cambio un tipo de asociación entre estados 5 .

¿En qué consiste? Esta forma de gobierno, señala Montesquieu, consiste «en un convenio, según el cual, varios cuerpos políticos consienten en convertirse en ciudadanos de un estado mayor que se proponen formar ${ }^{6}$. Se trata, al fin de cuentas, de «una sociedad constituida por otras sociedades y susceptible de ir aumentando en virtud de la unión de nuevos asociados»» ${ }^{7}$. Compuesta por pequeñas repúblicas, continúa diciendo el autor francés, goza de la excelencia del gobierno interior de cada una $\mathrm{y}$, respecto al exterior, tiene todas las ventajas de las grandes monarquías en virtud de la asociación ${ }^{8}$. Desde esta perspectiva, señala que Holanda, Alemania y la Liga Suiza están consideradas «en Europa como repúblicas eternas».

Por el contrario, el principio constitucional en que se fundamenta el estado federal es la pluralidad de centros de poder soberanos coordinados entre sí, de tal manera que el gobierno federal (nacional), competente respecto de todo el territorio de la federación, se le confiere una cantidad mínima de poderes indispensables para garantizar la unidad política y económica, y a los estados fe-

4 Federar, fin del siglo XIX; tomado del latín foederare, «unir por medio de una alianza». Derivado de foedus, «tratado, pacto», «alianza». Derivado, federación, 1463, no se hizo frecuente hasta el siglo XIX, latín foederatio, onis, «alianza». Federal, 1843, federalismo, federalista. Federativo. Confederar, hasta 1460, latín confoederare, «unir por tratado», «asociar», confederación, 1469, confederativo. Corominas, 1987: 270.

5 Bobbio, Matteuci, 1985: 349.

6 Montesquieu, 1984: 125.

7 El tema del federalismo surge en Montesquieu de una preocupación de la época, la seguridad. El título del libro IX, dedicado al mismo es harto elocuente: «De las leyes en su relación con la fuerza defensiva». Montesquieu, 1984: 125.

8 Montesquieu, 1984: 126. 
derales, competentes cada uno en su propio territorio, se les asigna los poderes restantes. Sobre esta base, la atribución al gobierno federal del monopolio de la competencia relativa a la política exterior y militar permite eliminar las fronteras militares entre los estados, de manera que las relaciones entre los estados «pierden el carácter violento y adquieren un carácter jurídico y todos los conflictos pueden resolverse ante el tribunal $»^{9}$. Las atribuciones de la soberanía tanto la de los estados particulares como la del gobierno nacional (federal), conservan su autonomía y poder, pero sin anular la idea esencial y básica de que el objetivo final de esas decisiones es claramente la de preservar el interés nacional. Dentro de esta perspectiva, Natalio Botana ha puntualizado, en un brillante texto sobre historia de las ideas por otra parte, que el nuevo federalismo debería entenderse como una forma política imaginativa que pudo asociar dos instancias de poder autónomos, esto es, como un verdadero "proyecto de concordia entre la soberanía establecida de los estados y la soberanía emergente del gobierno nacional» ${ }^{10}$.

Pues bien, ¿qué separa entonces a una confederación de un estado federal? Al respecto, el jurista holandés Kranenburg señala un aspecto fundamental que claramente los distingue ${ }^{11}$.

«el mejor criterio para diferenciar un estado federal y una confederación descansa en responder la pregunta de si los ciudadanos de un estado pequeño son o no afectados directamente por las leyes de los órganos legislativos del todo compuesto. En un estado federal los órganos centrales poseen derechos y obligaciones directos con respecto a los ciudadanos, mientras que en una confederación los derechos y obligaciones de los órganos del todo se realizan sobre las partes constituyentes y no sobre los ciudadanos» ${ }^{12}$.

En suma, el estado federal modifica el edificio político confederal, lo pone patas arriba. De esta manera, luego de este breve rodeo por algunos rasgos de la cultura política del periodo, estamos ahora mejor situados para entender que la presencia de Artigas en ese escenario juega un papel entre aquellos que optan por las tendencias autonomistas y federales frente aquellos, como las administraciones porteñas (Juntas o Directorios), quienes siguen el camino del centralismo político.

En ese marco, hay que comprender también que el frente centralista no tiene siempre las mismas creencias, las actitudes de sus partidarios no transitan

9 Bobbio, Matteuci, 1985: 688.

10 Botana, 2005: 91.

11 Sobre las ideas de federalismo, véase Chiaramonte, 1997; Botana, 2005: 66 a 107; Souto, 2008: 175-194.

12 Mascareños, 1952. 
por una línea recta. Si bien los que gobiernan sí lo hacen, por el contrario, los que aparecen en algunos momentos en los espacios de oposición, optan a veces por una política ambigua en donde la voz federal, por ejemplo, juega un papel. Como lo he tratado de mostrar en otro estudio, algunos morenistas como Bernardo Monteagudo, apelan justamente a los derechos de confederación de las provincias en ámbitos de opinión no oficiales como la Sociedad Patriótica, particularmente entre fines de 1811 y durante casi todo el año siguiente. Por este motivo, no es extraño que agentes artiguistas, como Santiago Cardoso, mantengan contactos con ellos y participen en el interior de esos ámbitos, como oradores en la Sociedad Patriótica o que colaboren en su diario. Esa ambigüedad, sin embargo, se rompe en algún momento. En el caso de Monteagudo y sus colegas de la Sociedad Patriótica, se da justamente en octubre de 1812 cuando cae el primer Triunvirato. Los miembros de ella y los de la Logia, van a sostener a partir de ese momento una línea política centralista que puede advertirse claramente en su participación en la administración central y en las instrucciones de los diputados de Buenos Aires en la Asamblea del año XIII. Es aquí donde los artiguistas son desplazados y perseguidos.

\section{I.1. ¿Quiénes son los artiguistas de Buenos Aires? Indicios}

Es difícil precisar la cantidad con exactitud. No obstante, con certeza, es posible distinguir algunas de sus actividades desarrolladas en el espacio urbano. Se trata de actores que poseen perfiles diferentes. He detectado, para decirlo directamente, a un oficial del ejército, a religiosos y letrados, y a diputados en las Asambleas nacionales de los años 1812 y 1813 . Pero también hay agentes que operan de manera anónima, e incluso algunos de ellos cuentan con varios centenares de firmas (de conocidos vecinos de la ciudad) que bien podrían servir como apoyo para algún reclamo político.

Quizás los nombres de los miembros más importantes sean los de Santiago Cardoso, Bruno de Rivarola y Vicente Fuentes, quienes se mueven allí en forma conjunta como una suerte de asesores políticos del líder oriental. El primero de los nombrados es la figura principal. De su trayectoria me ocupo puntualmente más abajo. De los otros dos dispongo de menos información. Fuentes, por ejemplo, es un oficial del ejército que tiene una relación directa con el gobierno de Buenos Aires. Sin embargo, no tengo noticias directas referidas a esas escenas que transcurren en el corazón del poder. Lo que se sabe, se sabe por los dichos de Rivarola y Cardoso, que en la correspondencia que mantienen con su jefe político, señalan puntualmente algunos de sus actos. Bruno de 
Rivarola, por el contrario, es un letrado reconocido en ambas orillas del Plata que ocupa lugares de relevancia en esta ciudad. Se conoce, por ejemplo, que es designado por el Triunvirato como diputado por la Banda Oriental para la Asamblea de abril del año 1812. En ese ámbito defiende la idea de independencia impulsada por Artigas. Poco tiempo más tarde, es uno de los seis diputados artiguistas designados para integrar la Asamblea del Año XIII ${ }^{13}$. En Buenos Aires, además, están presentes por esos días los otros representantes de esa fracción: además de Felipe Cardoso, están allí Mateo Vidal, Marcos Salcedo, Dámaso Antonio Larrañaga y Juan Dámaso de Fonseca. Todos son impugnados por la asamblea, salvo este último que es admitido y puede desempeñar su función dentro del recinto.

Como lo he insinuado ya, de los actores individualizados me ocupo en otro estudio puntual ${ }^{14}$. A continuación examino puntualmente a una de las figuras más relevantes.

\section{I.2. El caso de Felipe Santiago Cardoso}

Como ha demostrado Flavio García, Felipe Santiago Cardoso nace en la ciudad de Buenos Aires, el 1 de mayo de 1773. Su ámbito familiar es la de un notable de la última etapa colonial. Su padre, José, «fue un importante hacendado regional, que llegó a ocupar cargos del Cabildo, Justicia y Regimiento de Montevideo, tales como Depositario General y Alcalde de 1. ${ }^{\text {er }}$ voto a fines del siglo XVIII. Poseyó tierras en diversas zonas del país y solares heredados frente a la ciudadela» ${ }^{15}$.

Ese rasgo relevante, el de un hombre notable, lo acompaña y lo distingue a lo largo de toda su trayectoria vital. Su condición económica y social ha sido señalada casi en esos términos al definirlo justamente como uno de los «grandes y antiguos latifundistas», en la medida que figura como uno de los encum-

13 Actas del extinguido Cabildo de Buenos Aires, serie IV, Archivo General de la Nación. Véase en particular las sesiones de abril de 1812. Puede consultarse además, Reyes Abadie, 1994: 32. Cabe aclarar que Rivarola dejará, con el tiempo, de formar parte del artiguismo para integrar las filas del federalismo porteño (en la facción de Soler). Este aspecto lo he abordado en Herrero, 2008.

14 Herrero, 2008.

15 «En 1799 denunció terrenos entre los ríos Tacuarembó Grande y Chico, en el Yaguarí y Caraguatá, para sí mismo, su hijo Felipe, y para Antonio Pereira. En carta testamentaria de 1818, Don Felipe afirmó tener una estancia en Tacuarembó Grande, sus ranchos, corrales, y haciendas alzadas, que "tomó por denuncia a don José Artigas". Debe referirse a las asignaciones agrarias realizadas por éste en 1808 en esa región.» García, 1980: 12-13 (agradezco a Ana Frega el haberme advertido y facilitado esta información). 
brados integrantes de la Junta de Hacendados de la Banda Oriental ${ }^{16}$. Esta privilegiada situación económica y social se corresponde también con su destacada situación política y militar.

Sus comienzos, como es habitual en otros actores de la época, es en el ámbito militar. A decir verdad, su situación es la situación de un verdadero pionero en cuanto figura como uno de los primeros capitanes blandengues. Precisamente en ese ambiente forma amistad durante diez años con un hombre que posteriormente se convierte en uno de los polos de la política regional: José Artigas ${ }^{17}$. Exactamente, el 23 de diciembre de 1797, ingresa con el grado de capitán, al haber proporcionado al regimiento una de las ocho compañías de «beneficio» exigidas justamente para su fundación ${ }^{18}$. Más tarde ocupa una posición relevante en las invasiones inglesas. Sus movimientos resultan verdaderamente activos, en cuanto se tiene conocimientos precisos sobre su actuación en la mayoría de las operaciones previas a la ocupación británica de Montevideo el 3 de febrero de $1807^{19}$. Esta etapa de su vida es ciertamente la de un hijo de un notable rioplatense, en la medida que, como lo ha mostrado Tulio Halperin, no escapa a la estrategia preferida por los notables criollos para sus hijos en el último periodo colonial ${ }^{20}$.

El primero de mayo de 1810 cambia de destino: Buenos Aires ${ }^{21}$. Su actividad militar se combina con su acción típicamente política. Pues bien, ¿cuál es su participación? ¿En qué condición lo hace? ¿Qué postura asume en esos días de conflictos cruzados? Se sabe que es uno de los 252 vecinos convocados al Cabildo abierto del 22 de mayo, quienes tienen como principal misión deliberar y decidir sobre la nueva situación política ante la invasión de Napoleón en España. Su participación reviste características precisas y particulares. Lo

16 De la Torre, Rodríguez, Sala de Touron, 1969: 121.

17 Es difícil precisar cuando Cardoso puede ser calificado de artiguista. La relación de su familia con Artigas parece datar de fines del siglo XVIII. Todo parece indicar que uno de los primeros encuentros fue en las filas militares. «Con seguridad, dice un especialista, desde otoño de 1797 data su vinculación con Artigas. Éste se había iniciado en los Blandengues el 10 de marzo. Felipe Cardoso ingresó al mismo como Capitán el 23 de diciembre, al haber proporcionado al regimiento una de las ocho compañías de "beneficio" exigidas para su fundación». García, 1980: 13-14.

18 García, 1980: 13. A punto de cumplir los veinticinco años de edad, el ascenso de Cardoso se produjo «por el servicio que hizo de presentar cien hombres vestidos, y de caballos cada uno, para la formación del referido cuerpo». García, 1980: 13.

19 García, 1980: 15.

20 Halperin Donghi, 1979: 123-167.

21 El 1 de mayo de 1810, en plena agitación política, su jefe Ramírez de Arellano certifica su «destino: Buenos Aires». Llevaba en su despacho de teniente coronel firmado por el ex Virrey Santiago Liniers. García, 1980: 16. 
hace en su calidad de militar, «Teniente Coronel urbano». Su intervención no pasa en silencio. En esa célebre reunión, adopta finalmente la postura que siguieron más de las dos terceras partes de los concurrentes invitados, esto es, la subrogación del Virrey en el mando (con diversos matices agregados para encarar la sustitución) $)^{22}$.

Cardoso, por cierto, sigue alerta a los hechos y movimientos de esa crucial semana, acompañando la preocupación militar del nombramiento de la Junta presidida por Saavedra en nombre del pueblo bonaerense. Tal situación se hace enteramente visible si tenemos presente que su nombre figura entre los cuatrocientos firmantes del petitorio correspondiente suscrito en la Plaza de la Victoria, y en forma conjunta con otros treinta y ocho asistentes y votantes al Cabildo Abierto del 25 de mayo de $1810^{23}$.

Pero eso no es todo. Posteriormente, continúa sus tareas como un hombre de la Revolución al ser enviado a ocupar la Comandancia militar de Colonia. Si bien el hecho no es del todo claro, sí se sabe que el intento fracasa, ya que no consigue asumirlo, y a su vuelta a Buenos Aires, es separado del servicio ${ }^{24}$. A la espera de su reincorporación (objetivo que nunca logra) se vincula con los grupos ilustrados de Buenos Aires ${ }^{25}$.

Como ya habrá advertido el lector, fue necesario alejarnos en el tiempo ya que de ese modo resultó enteramente posible mostrar con incontestable claridad que Cardoso no llegó a la ciudad-puerto de un momento para otro, esto es, no fue un recién llegado, un arrivista. Por el contrario, se trata de alguien nacido allí, con un pasado de hombre notable que explica en buena medida su situación posterior. Durante ese periodo, se ha visto cómo asimismo establece su relación con Artigas y con los sujetos de poder de Buenos Aires. Y precisamente como un notable de la época elige la carrera militar, en donde juega un papel destacado, y figura como uno de los protagonistas de la Revolución de Mayo.

En las páginas que siguen me interesa analizar su vinculación con los sectores morenistas y sus primeras actividades como agente artiguista en Buenos Aires, posteriormente, exploro su tarea política como diputado en el marco de la Asamblea del año XIII.

22 García, 1980: 19-21.

23 García, 1980: 21.

24 García, 1980: 23-26.

25 García, 1980: 27. 


\section{En la Sociedad Patriótica y en la Asamblea del AÑo XIII. UN ARTIGUISTA CON PASADO MORENISTA}

Su vinculación con el sector morenista puede percibirse por sus actos decididamente contrarios al movimiento de los orilleros de abril de 1811, por su actividad (un año después) dentro del ámbito de la Sociedad Patriótica, y, por su participación (exactamente en el mes de octubre) en el movimiento de Pueblo que empuja fuera de la zona central de poder al Primer Triunvirato ${ }^{26}$. A decir verdad, ese contacto y esa simpatía no pasa inadvertida en las páginas de algunos especialistas, quienes si bien no abordan el tema como aquí se presenta, sí abiertamente sostienen que durante ese periodo nuestro escritor es «partidario notorio de Mariano Moreno» ${ }^{27}$.

¿Cuándo Cardoso opera políticamente para el caudillo oriental? Se sabe con certeza que ese tipo de vínculo e intervención se da durante el año 1812 y 1813. Entre sus pertenencias, que son retenidas cuando cae preso en el mes de julio de ese último año, pueden advertirse algunas cartas que ellos intercambian e incluso algunos borradores de textos sin enviar. El detalle puntual es el siguiente: «Tres cartas de Artigas a Cardoso, 2 de abril, 19 de mayo y 15 de junio de 1812.-dos medios pliegos borradores de cartas escritas por Cardoso a Artigas, 23 de setiembre y 26 de noviembre de $1812 »^{28}$. Incluso se retiene una «Licencia de Artigas a Cardoso para pasar a esta Capital, 4 de enero último $(1813)^{29}$.

Durante ese año, nuestro actor participa en las sesiones de la Sociedad Patriótica. Es probable que por un lado su vinculación con el sector morenista haya ayudado de alguna manera para que se le permitiera ser socio y participara de modo activo en sus reuniones. Por otro lado, su inserción en ese círculo ilustrado no es extraño si tenemos presente que tiene una trayectoria pública en la ciudad con los grupos notables y que, al mismo tiempo, está en los acontecimientos más relevantes desde las Invasiones Inglesa o la Revolución de Mayo, hechos que sugieren que su actuación en la reuniones de la Sociedad no pueden resultar extrañas.

26 Por razones de espacio no examino aquí la participación de Cardoso en las jornadas de abril de 1811, sí lo hago en un estudio particular. Herrero, 2008.

27 Ibarguren (hijo), 1961: 95. Otro investigador también sugiere su vinculación con los sectores morenistas. García, 1980: 27.

28 «Detalle de la documentación y dineros hallados en la casa de Felipe Santiago Cardoso», Buenos Aires, 27 de julio de 1813. En $A A$, T. XI.

29 «Detalle de la documentación y dineros hallados en la casa de Felipe Santiago Cardoso», Buenos Aires, 27 de julio de 1813. En AA, T. XI. 
¿Qué participación tiene? ¿Es secundaria, lateral, o bien lo hace de un modo central, alcanzando cierto protagonismo? No es un integrante más, o alguien que pasa simplemente desapercibido. Algunos de sus discursos aparecen en el órgano periodístico de ella: El Grito del Sud ${ }^{30}$. Así, en las páginas de ese diario se describe su accionar en alguna de sus sesiones, en momentos en que Bernardo Monteagudo es el Secretario de la misma. «El ciudadano Cardoso -afirma el redactor-, leyó ... una memoria, en que también se propuso probar, que la falta de una constitución era el origen de nuestros males... $\rangle^{31}$. En esa misma lectura menciona en términos generales algunos ejemplos federales: «Sería también muy bueno se publicasen, continúa nuestro escritor, las constituciones de los Estados Unidos de Norteamérica, los que ha formado la nación Venezolana, y los que han hecho célebres y felices a otras repúblicas, en lo antiguo y en lo moderno.» $\rangle^{32}$

Como se ve, no sólo interviene como un miembro más de la Sociedad Patriótica sino que coincide en dos de sus principales banderas: constitución e independencia ${ }^{33}$. En un estudio anterior, he tratado de probar que en el esquema argumental del máximo referente de la oposición, Bernardo Monteagudo, se entrecruzan no sólo esas dos nociones, sino que ellas se conectan con la idea de un gobierno federal. Estos datos, por cierto, nos ayudan a entender el contexto en el que actúa nuestro escritor, esto es, por qué un artiguista puede encontrar un espacio en donde su discurso político puede hallar oídos dispuestos a escucharlo.

Ese conjunto de ingredientes políticos se perciben en una acción concreta en la que la Sociedad Patriótica cumple un rol principal, el Movimiento de Pueblo de octubre. Con certeza sabemos que Cardoso está presente en la Plaza de Mayo y que firma la Representación que allí se redacta ${ }^{34}$. ¿Quién es su principal impulsor? ¿Qué resultados políticos tiene? ¿Qué cuestiones se plantean? El principal promotor de ella es Monteagudo, quien encabeza con su firma dicho documento. El resultado es exitoso, en cuanto se disuelve tanto el Primer Triunvirato como la Asamblea que se constituye en ese momento ${ }^{35}$. Bajo el título de «Manifiesto del gobierno», se publica en La Gazeta un texto de directa

30 «Prospecto», El Grito del Sud, 1812.

31 «Reflexiones que dirige a la Sociedad Patriótica literaria un socio de ella», El Grito del Sud, 13 de octubre de 1812.

32 «Reflexiones que dirige a la Sociedad Patriótica literaria un socio de ella», El Grito del Sud, 13 de octubre de 1812 .

33 Sobre la necesidad de independencia puede leerse. «Sin título», El Grito del Sud, 17 de noviembre de 1812.

34 «Manifiesto del Gobierno», La Gazeta, 22 de octubre de 1812.

35 «Manifiesto del Gobierno», La Gazeta, 22 de octubre de 1812. 
redacción por parte de los grupos opositores de Buenos Aires, en donde es posible leer la expresión «las provincias confederadas» como sinónimo de alianza preexistente. Así, refiriéndose a este suceso se afirma allí:

«Congregados pacíficamente en las galerías de la casa consistorial los eclesiásticos más respetables, los empleados civiles, los ciudadanos ilustrados, y la parte más honrada de todas las clases del vecindario, dirigieron al Excmo Ayuntamiento una representación que entre otras cosas pedía, que reuniendo el Cabildo las facultades del Pueblo, nombrase un nuevo gobierno provisorio, hasta la convocación de una asamblea general extraordinaria que debía fijar la suerte de las provincias confederadas.» ${ }^{36}$ (Cursiva mía).

Las cosas aparecen sustancialmente sugeridas, sólo se subraya la preexistencia de hecho de la unión de las provincias, y la igualdad de derechos de estas para elegir el futuro gobierno ${ }^{37}$. No se menciona si son parte de la nación española. Sospechamos que no, debido a que se trata de grupos que buscan en esos instantes la independencia ${ }^{38}$. No es el mismo empleo que se hace durante 1811 cuando se apela al Rey ${ }^{39}$. De este modo, antes del 8 de octubre, para obtener el apoyo de las provincias, al menos pasivo, se invoca el concepto de confederación poniendo especial énfasis en los derechos igualitarios de aquéllas. Sin embargo, luego de que el movimiento se imponga, la realidad política muestra una cara diferente a la imaginada antes de la llamada «Revolución de octubre». Un poco más tarde, la idea de concentración del poder retorna a escena, y los nuevos administradores ya no hacen ningún tipo de mención sobre los derechos de los pueblos ${ }^{40}$. Prueba evidente de este hecho, es la propuesta constitucional de los diputados de Buenos Aires para la Asamblea del Año XIII, en donde se destaca la «indivisibilidad del estado» ${ }^{41}$.

Desde octubre de ese año y durante el año 1813, sus movimientos pierden fuerza pero sobre todo visibilidad pública debido a que la relación entre el nuevo gobierno central y Artigas se deterioran por esos días. ¿Por qué? Por que desde enero sesiona la Asamblea del año XIII y la postura centralista de poder de Buenos Aires y la federal de Artigas chocan frontalmente en el do-

36 «Manifiesto del Gobierno», La Gazeta, 22 de octubre de 1812.

37 Proclama de los que se alzan el 8 de octubre, allí se habla de «los derechos de los pueblos confederados». «Excmo Ayuntamiento de la Capital de Buenos Aires», La Gazeta, 22 de octubre de 1812. En el Acuerdo del cabildo de Buenos Aires del 8 de octubre del mismo año se reproduce este mismo manifiesto. Acuerdos del Extinguido Cabildo de Buenos Aires, Serie IV, tomo V, 1812-1813: 354.

38 Halperin Donghi, 1979: 168-186. González Bernaldo, 3 (Buenos Aires, 1991): 7-29.

39 Herrero, 2008. Véase capítulo 2.

40 Halperin Donghi, 1979: 168-186.

$41 A A$, véase especialmente tomo IX. 
minio público. Es uno u otro. Que esto es así lo prueban las persecuciones que deben padecer los partidarios de aquel signo político ${ }^{42}$. Con el tiempo, esta situación empeora aún más. Exactamente, en febrero de 1813, se cortan abruptamente las comunicaciones entre aquéllos ${ }^{43}$. Los artiguistas, como así también otros grupos que no se adaptan a los nuevos tiempos, quedan aislados. Bien podría decirse que han quedado desguarnecidos, parados bajo cielo abierto.

En suma, su vinculación con el sector morenista parece datar del movimiento de abril de 1811, aunque seguramente sus contactos son anteriores, su intervención más directa como artiguista se da en el espacio de la Sociedad Patriótica. Ese vínculo, finalmente, parece romperse cuando Monteagudo y otro lideres morenistas optan por cambiar el paso, y forman parte del llamado partido fuerte de Alvear, que, como se ha dicho ya, no reconoce los principios constitucionales independentistas iniciales.

Su actividad pública no culmina allí. Como representante de Artigas, Cardoso realiza, asimismo, reuniones de carácter político y militar con integrantes del gobierno central ${ }^{44}$. Su rol cobra más resonancia e impacto unos meses más tarde cuando sea elegido diputado artiguista.

El 15 de abril de ese año, les son extendidas a nuestro escritor sus credenciales para asistir en la ciudad de Buenos Aires a la Asamblea Constituyente en calidad de diputado por Canelones y su jurisdicción, a la vez que se le entregan sus «Instrucciones».

¿Por qué se adopta esta resolución? Todo parece indicar que la respuesta tiene una clave política. Según los historiadores artiguistas, la explicación debe buscarse en que Buenos Aires y la Banda Oriental tienen objetivos muy diferentes ${ }^{45}$. La primera persigue una forma de poder centralista, es decir, continuar con la estrategia desplegada desde los inicios de la Revolución: Buenos Aires debe mantener al mismo tiempo la sede capital de la nación y procurar el férreo control del gobierno nacional. Como señalo detalladamente más adelante, el planteo artiguista se basa en las Instrucciones dadas a sus diputados, esto es, una plataforma confederal republicana y constitucional que ciertamente se

42 Reyes Abadie, 1994: 82.

43 Reyes Abadie, 1994: 82-84.

44 En una carta ya citada escrita por Cardoso, pone de manifiesto los manejos del gobierno de Buenos Aires tendientes a usurpar su posición en la Banda Oriental y adueñarse de ella. Le previene contra esas maniobras, con las que se intenta incluso quitarle la vida, por lo cual le aconseja «que no se fíe de nadie». Véase, «Carta de Felipe Cardoso a Artigas», Buenos Aires, 4 de diciembre de 1812 , en $A A$ : 148-149, T. IX.

45 García, 1980. 
presenta como una oferta ideológica alternativa a la propuesta centralista imaginada desde la otra orilla del Plata.

\section{II.1. Las creencias federalistas}

Distintos indicios nos permiten verificar cuáles son los componentes ideológicos que, entre los años 1812 y 1813, Cardoso difunde desde la ciudad de Buenos Aires. Se ha visto ya, cómo durante ese primer año promueve las ideas de confederación, independencia y constitución, las cuales pueden detectarse tanto en su participación en las reuniones de la Sociedad Patriótica como en las páginas de El Grito del Sud. Ellas son, además, algunas de las bases ideológicas que posteriormente animan el Movimiento del Pueblo exitoso de octubre.

En el transcurso del año 1813 emplea dos tipos de materiales políticos diferentes que son necesarios examinar. En primer lugar, tiene a su disposición las instrucciones de abril y las llamadas pretensiones artiguistas, las cuales constituyen el ideario político federal que los diputados, como Cardoso, no sólo tienen como mapa político básico sino que, según lo resuelto en las jornadas en donde se las elabora y define, debe rápidamente difundirse al resto de los territorios provinciales. Por esta última acción, recordemos, en el mes de julio, es detenido por agentes de las fuerzas de seguridad porteña. Los papeles federalistas que llevan consigo los diputados para su amplia reproducción y divulgación constituye, por consiguiente, nuestro primer punto de análisis. En segundo lugar, es necesario precisar y determinar qué fórmula política subyace en el manuscrito constitucional hallado en su casa en momentos de su allanamiento. ¿Se trata de un escrito político uniforme, esto es, tiene un fondo federalista común o bien estamos en presencia de variantes diferentes de ese signo? ¿Son iguales las líneas ideológicas impulsadas por Cardoso en el año 1812 que las reproducidas durante el año 1813 ?

\section{II.1.1. La propaganda política elaborada en abril de 1813}

El día 5, Artigas, como es sabido, inaugura con un discurso el Congreso de Las Tres Cruces. Los representantes reunidos allí formulan un «compromiso» que queda finalmente fijado y determinado en las llamadas «ocho condiciones». $\mathrm{Y}$ es precisamente en función de ese compromiso recién adquirido que sólo

46 García (1980): 37-38. 
unas jornadas más tarde se discute y redacta las instrucciones a los diputados artiguistas, las cuales están compuestas exactamente por veinte artículos ${ }^{46}$.

¿Cuáles son los principios básicos que subyacen en esas instrucciones? En el artículo 1 se sostiene la independencia absoluta de estas colonias, «absueltas de toda obligación de fidelidad a la Corona de España y familia de los Borbones» ${ }^{47}$. Es conocido que dicha cuestión está en el centro de la mesa de discusión pública desde los inicios de la Revolución. En los hechos, sin embargo, la única política que se aplica es la de dictar leyes impulsadas y sancionadas por Juntas y Triunviratos a nombre de los poderes de Fernando VII ${ }^{48}$. Tampoco hay que pasar por alto que las actuales autoridades de Buenos Aires toman el poder por asalto en octubre de 1812, anunciando, en ese recreado escenario, la próxima sanción de una constitución y la declaración de la independencia. Ninguna de estas medidas son adoptadas. En este contexto de falsas promesas, debe entenderse justamente la propuesta artiguista que pretende, por cierto, interrumpir esa línea que casi naturalmente los gobiernos de turno vienen imponiendo.

¿Qué forma de gobierno señalan? La forma de gobierno es la de la confederación republicana de Estados, unidades estatales que deben, por cierto, mantenerse en una firme liga de amistad y alianza. En este sentido, «el gobierno supremo, establece las mismas instrucciones, entenderá solamente en los negocios generales del Estado. El resto es peculiar al gobierno de cada provincia» ${ }^{49}$. Como puede apreciarse, el gobierno nacional se hace cargo únicamente de los llamados «negocios generales», los asuntos generalmente vinculados con la paz y la guerra entre las provincias y los estados extranjeros. No obstante, los atributos mas sobresalientes quedan señalados para las provincias. Por lo demás, y como es habitual en este tipo de códigos escritos, deben distinguirse y especificarse en él los llamados derechos fundamentales del hombre y las libertades, religiosas, civiles, económicas, los cuales serán concebidas en su máxima extensión ${ }^{50}$.

47 García (1980): 32-33.

48 García (1980): 32-33.

49 Así lo establecen los dos pliegos de Instrucciones del 5 y 13 de abril de 1813. García (1980): 33. Según los artículos 16 y 17 de las Instrucciones orientales del 13 de abril, se sostiene la igualdad de las provincias, sus garantías contra la fuerza, su constitucionalización y parlamentarización local como entidades territoriales autárquicas. García (1980): 34. «La Constitución garantizará a las Provincias Unidas una forma de gobierno republicano», así lo establecía el artículo 20 de las Instrucciones de Artigas a sus diputados del 13 de abril de 1813. Demicheli, 1962: 33.

50 El artículo 3 de las Instrucciones del 13 de abril se sostiene que «promoverá la libertad civil y religiosa en toda su extensión imaginable». García (1980): 33. 
En claro contraste con las formas que adquiere el poder desde la Revolución de Mayo, se adopta la división tripartita del poder público, en la nación y en la provincia, con un Legislativo Bicameral, los cuales «jamás podrán estar unidos entre sí y serán independientes en sus facultades $\rangle^{51}$. ¿Cuál es la forma de su designación? Los miembros de esos poderes no son designados de forma directa ya que se emplea el sistema de representación política, es decir, a partir de elecciones «libres y públicas» ${ }^{52}$, que se realizan tanto en el orden local como nacional.

Como se ve, una y otra vez se hacen visibles las ventajas de la sanción de un código escrito que contenga una serie determinada y precisa de normas jurídicas orgánicamente relacionadas entre ellas. La ventaja de que sean escritas es para impedir justamente aquello que constituye una queja permanente en algunos gobiernos de provincia, esto es, por un lado la irrupción de gobiernos despóticos y por otro lado la preparación del terreno para la construcción de un gobierno moderado como es el que los federales predican. En este sentido, como lo ha puesto de relieve Nicola Matteucci, la constitución no sólo regula el funcionamiento de los organismos de la maquinaria estatal, sino que además consagra los derechos de los ciudadanos, puestos como claros límites frente al poder del Estado ${ }^{53}$. Es precisamente dentro de este cuadro, salpicado de líneas proclives a establecer límites y garantías, en donde debe entenderse que para evitar posibles fuentes de conflicto el artículo 18 dispone que mediante trabas constitucionales «se aniquilará el despotismo militar, asegurándose así la inviolabilidad de la soberanía de los pueblos» $\rangle^{54}$.

En el trasfondo de esta ingeniería política está también la preocupación por el lugar en donde debe instalarse la sede capital. El artículo 19, sostiene claramente que la misma puede ubicarse en cualquier dominio fuera de los límites de la ciudad de Buenos Aires ${ }^{55}$. El tema no constituye una cuestión ciertamente menor. El largo lamento sobre la acción desplegada por los gobiernos porteños y su privilegiada situación de disponer de dichas autoridades nacionales en su propio territorio puede verificarse desde los comienzos de la emergencia revolucionaria. La instalación del Congreso Constituyente del año 1816 en la ciudad de Tucumán se debe exactamente a ese motivo. Pero también es parte de los reclamos de los confederacionistas que se alzan en Buenos Aires contra la nueva designación de Pueyrredón en ese mismo año y, durante el crítico

\footnotetext{
51 García (1980): 33.

52 García (1980): 33.

53 Matteuci (1998): 25.

54 Matteuci (1998): 40.

55 Matteuci (1998): 40.
} 
año 20, retorna a escena como un ingrediente más del discurso de ese mismo signo ideológico ${ }^{56}$.

Armar una maquinaria política confederacionista implica dotar de atributos precisos y concretos a las partes que la nutren en forma esencial. En este caso, esas partes esenciales, son espacios provinciales. La provincia, establece el artículo 11, retiene su soberanía, libertad, independencia, poder, jurisdicción y derechos que no sean expresamente delegados a la confederación por las provincias juntas en Congreso ${ }^{57}$. Según el artículo 17, ellas tienen derecho a levantar los regimientos que necesite, nombrar oficiales, reglar su milicia para su seguridad y libertad, «por lo que no podrá violarse el derecho de los pueblos para guardar y tener armas $\rangle^{58}$.

Las instrucciones contienen disposiciones que hacen a la Provincia Oriental, como, por ejemplo, que los puertos de Maldonado y de Colonia puedan realizar un intercambio comercial con el exterior (artículos 12 y 13), y que no se dicte ninguna ley sobre bienes extranjeros que mueren $a b$ intestato, sobre multas y confiscaciones que antes se aplicaban para el rey, etc. (artículo 15) ${ }^{59}$. Los artículos 12 y 13 de las Instrucciones del 5 de abril de 1813, sostienen la libre navegación de los ríos y el tránsito libre por todo el territorio. Así se oponen a Buenos Aires, que mantiene durante medio siglo su puerto exclusivo con su sola y única aduana centralizada para todo el Virreinato.

En suma, frente al proyecto revolucionario que emerge en tierra bonaerense, exactamente, en el año 1810, y que tiene como elementos básicos de su experiencia (aunque no únicos ni exclusivos), a la centralización del poder y a la subordinación de los pueblos a una autoridad de carácter nacional radicada en la propia ciudad porteña, surge, hacia 1813, lo que Tulio Halperin ha denominado como la «otra revolución». Enmarcada en una clara postura independentista, el flamante plan, es en rigor un experimento confederacionista constitucional y republicano, con una división clara de poderes y en donde se deja abierta la posibilidad de que cualquier provincia pueda ejercer el derecho de ser sede capital.

La necesidad de incrementar la propaganda federalista es esencial, ya que forma parte de una táctica, tan precisa como decisiva, en el marco de la disputa por el poder dentro de la Asamblea que sesiona en Buenos Aires desde enero. Carlos Segreti, en este preciso sentido, ha señalado justamente que Artigas «ha planeado toda una estrategia basada en aritmética política» ${ }^{60}$. ¿En qué

\footnotetext{
56 Herrero, 2007.

57 Segreti, 1980: 39.

58 Segreti, 1980: 34.

59 Segreti, 1980: 41.

60 Segreti, 1980: 36.
} 
consiste? El caudillo oriental confía en poder apoderarse enteramente de las palabras y de los sueños de los diputados de los pueblos del ex virreinato del Río de la Plata. Precisamente, el 17 de abril, explica al gobierno paraguayo el equilibrio del «fuego de los sufragios en la Asamblea, con seis diputados nuestros (de la Provincia Oriental), siete de esa provincia grande (Paraguay) y dos de Tucumán, cuyos cabildantes habían estado curiosamente en contacto con Cardoso, decididos al sistema de confederación ${ }^{61}$. Pero eso no es todo. Hay un voto más. El diputado de Potosí, más tarde, también se manifiesta a favor del federalismo ${ }^{62}$.

Se despliega de esta manera una estrategia política de persuasión que he denominado federalismo de hecho, en la medida que se presentan estas ideas como si ya están impuestas en los propia realidad. Su finalidad es obvia, se trata de convencer y seducir con la idea de que no puede desconocerse lo que se da naturalmente en el espacio social. Esta lógica, por cierto, no es exclusiva de este contingente político, más tarde es empleada por los confederacionistas de junio de 1816 y por los federales de $1820^{63}$.

Ésta es la atmósfera política que, sin lugar a ningún tipo de dudas, abona el terreno para el surgimiento de una estrategia que tiene como uno de sus aspectos sobresalientes la propaganda y la divulgación. En ese marco, hay que entender entonces la puesta en funcionamiento de un movimiento político paralelo: por un lado, se explica mejor por qué Cardoso hace una intensa actividad propagandística en momentos en que se persigue claramente a los partidarios de Artigas en la ciudad capital, y, por otro lado, debe comprenderse por qué justamente las autoridades locales lo buscan, lo detienen, le inician una causa, y finalmente lo condenan.

Ahora bien, en qué consiste el proyecto de constitución federal que se encuentra en su domicilio. ¿Es el mismo? ¿Son complementarios?

\section{II.1.2. El llamado «proyecto federal»}

Si bien en el manuscrito constitucional sólo figuran sus iniciales (FSC), nos sumamos a los historiadores que insisten en adjudicársela a Cardoso ${ }^{64}$. Varios indicios parecen confirmarlo. Por una parte, esa documentación está en su casa y forma parte de su material de trabajo; por otra parte, las iniciales con

61 Oficio de Artigas al Gobierno de Paraguay, comunicándole los sucesos ocurridos en la

Banda Oriental. Delante de Montevideo, 17 de abril de 1813. Citado en García, 1980: 47.

62 Segreti, 1980: 49.

63 Herrero, 2007.

64 Street, 1967: 124-126. Demicheli, 1962: 109-110. 
que aparece firmada corresponden a su nombre completo. La situación puede deberse a que en esos días (como he señalado con insistencia ya) ocultar su identidad, usar letras indescifrables a simple vista o un seudónimo, está entonces en perfecta sintonía con el clima de persecución política que se vive en la ciudad. Por lo demás, es del todo probable suponer que esas numerosas páginas constitucionales las haya escrito o por lo menos las ha pensado en Buenos Aires, ya que justamente entre los años 1811 y julio de 1813, se encuentra casi todo el tiempo allí.

Ahora bien, ¿Qué podemos decir acerca de esa constitución federal ${ }^{65}$ ? En primer lugar que tiene un poco más de sesenta artículos y que toma en préstamo distintas ideas de documentos similares de la época ${ }^{66}$. Entre sus papeles se sabe que tiene las constituciones de Estados Unidos, la de Venezuela y una española. En una primera mirada parece que se trata de una simple copia ${ }^{67}$. Una rápida lectura por los códigos escritos en el último periodo colonial de Estados Unidos y la que redacta Cardoso, puede provocarnos ciertamente la sensación contraria, la utilización de términos y artículos completos extraídos de aquella experiencia constitucional resulta, por cierto, muy evidente.

Sin embargo, hemos podido verificar por un lado que utiliza párrafos casi completos de los «artículos de confederación» (primera Carta Magna de Estados Unidos), así como también los de la segunda constitución de la república del Norte de 1787; incluyendo además los correspondientes a la enmienda de esta última ${ }^{68}$. No obstante, una lectura más atenta nos muestra que, por otro lado, toma de todos estos textos aquello que le sirve, no considerando algunos temas e incluyendo otros. Sobre ellos vuelvo puntualmente al final de este parágrafo.

65 Artículo 1. «El título de esta confederación será: Provincias Unidas de América del Sud». Los límites geográficos aparecen nítidamente recortados: «Artículos de confederación y perpetua unión entre las provincias de Buenos Aires, Santa Fe, Corrientes, Paraguay, Banda Oriental del Uruguay, Córdoba, Tucumán. \&», En $A A$, T. 12.

66 Esta idea también es analizada por Demicheli, 1962: 32.

67 Se ha destacado la influencia de las constituciones de Estados Unidos y de las enmiendas en la redacción de esta constitución. Demicheli, 1962: 42-46.

68 De la primera constitución de Estados Unidos, pueden verse rastros de ella en los artículos 1 a 5, 27 a 35 y 64 de la Constitución de Cardoso. De la segunda constitución de Estados Unidos, pueden consultarse los artículos 6 a 26, 36 a 45 y 54 a 63 de la Constitución de Cardoso. Y de los artículos de enmienda de la segunda constitución, pueden verse los artículos 46 a 53 de la constitución de Cardoso. Resulta pertinente recordar que las primeras diez enmiendas fueron propuestas en el Congreso durante su primer periodo de sesiones, y ratificadas el 15 de diciembre de 1791. La enmienda undécima fue propuesta durante el primer periodo de sesiones del tercer Congreso y su ratificación fue anunciada por el Presidente de los Estados Unidos en el mensaje que dirigió al Congreso con fecha 8 de enero de 1798. En $A A$, T. 12. 
¿De qué tipo de constitución federal se trata? No faltan razones para afirmar que no se ajusta a los parámetros básicos de un modelo político confederal. Estrictamente reúne los ingredientes esenciales de un estado federal, en la medida que existen dos autoridades políticas, una nacional y otra que corresponde a las provincias ${ }^{69}$. La primera tiene un poder más fuerte y dominante que las segundas, en cuanto posee tanto atribuciones económicas como sobre las relaciones exteriores y de jurisdicción entre las provincias, pero también forman parte de ellas las decisiones sobre el ejército, entre otras, las cuales le son delegadas por las unidades provinciales. En línea con este orden de ideas, el artículo 28 es muy claro y terminante: dispone que ni dos o más provincias entrarán en algún tratado, confederación, o alianza entre sí, cualquiera que sea, sin el consentimiento de las Provincias Unidas juntas en congreso $^{70}$.

¿Qué otros aspectos merecen destacarse? La forma de gobierno es republicana, existe división de poderes y cada provincia dispone de la facultad de dictar su propia constitución. El territorio que menciona, son todas las provincias existentes en lo que se conoce bajo el nombre de las Provincias Unidas del Río de la Plata.

Una de las formas de comprender el modelo de Estado Federal, es, justamente, señalando cuáles son los atributos que el gobierno federal (nacional) dispone para sí. Para comenzar, anoto, entonces, algunos de los aspectos exclusivos del poder nacional con relación a los temas económicos: en el artículo 29 se precisa que ninguna provincia establecerá algunos impuestos o derechos que puedan chocar con algunas estipulaciones, tratados hechos por las provincias unidas juntas en congreso con algún rey, príncipes o Estado. En el artículo 35 se sostiene que el congreso tendrá poder para imponer tasas, derechos, impuestos y sisas, pagar las deudas, proveer a la defensa común y bien general de las provincias unidas, regular el comercio con las naciones extranjeras entre los diversos estados y provincias y tribus de los indios (pero todos los derechos, impuestos y sisas, serán iguales en todas las provincias unidas); tomar dinero prestado a crédito de las provincias unidas; establecer una regla uniforme de naturalización y leyes uniformes sobre el asunto de bancarrotas en todas las provincias unidas; acuñar moneda, regular el valor de ella y el del cuño extranjero, y fijar la tasa de los pesos y medidas entre las provincias unidas; regular el tráfico y manejar todos los negocios con los indios que no

69 Art. 2. Cada provincia retiene su soberanía, libertad e independencia, y todo poder, jurisdicción, y derecho, que no es delegado expresamente por esta confederación a las Provincias Unidas juntas en Congreso. En $A A$, T. 12.

70 AA, T. 12. 
sean miembros de algunas de las provincias unidas...; levantar y sostener ejér$\operatorname{citos}^{71}$.

Los problemas concernientes a las relaciones exteriores o de jurisdicción, también encuentran en el poder nacional su centro de decisión. Según el artículo 27, ninguna provincia sin el consentimiento de las provincias unidas juntas en congreso, mandará, o recibirá embajadas, ni entrará en conferencia, acuerdo o alianza, o tratado con ningún Rey, Príncipe o Estado. Asimismo, por el artículo 31, ninguna provincia se empeñará en alguna guerra sin el consentimiento de las provincias unidas juntas en congreso, a menos que la tal provincia sea actualmente invadida por enemigos. El artículo 34, dispone que las provincias unidas juntas en congreso, tendrán el solo y exclusivo derecho, y poder de declarar la guerra y hacer la paz (excepto en los casos mencionados en el artículo 31). Por último, el artículo 36 sostiene que el congreso será también el último resorte para las apelaciones en todas las disputas, y diferencias que susciten ahora o que puedan suscitarse en adelante entre dos o mas provincias; concerniente a límites, jurisdicción o alguna otra causa cualquiera que sea ${ }^{72}$.

Las principales decisiones en el orden militar son emitidas por el poder nacional. El artículo 30 sostiene que ningún buque de guerra se mantendrá en tiempo de paz por alguna provincia excepto aquel número solamente que se estimare necesario por las provincias unidas juntas en congreso, para la defensa de la tal provincia, o su tráfico; ni se mantendrá por alguna provincia cuerpo alguno de tropas en tiempo de paz, excepto aquel número solamente que a juicio de las provincias unidas juntas en congreso, se considerare indispensable para guarnecer las plazas necesarias a la defensa de la tal provincia. Pero todas las provincias mantendrán siempre una milicia bien reglada y disciplinada, completamente armada y equipada; y provendrán y tendrán constantemente pronto para el uso. Finalmente, en el artículo 33, se afirma que todos los gastos de la guerra y demás expensas que ocurrieren por la defensa común o prosperidad general, y permitidos por las provincias unidas juntas en congreso, serán costeados por la tesorería general de las provincias unidas ${ }^{73}$.

Llegados a este punto conviene volver, entonces, sobre la naturaleza de estas ideas federalistas. A decir verdad, Cardoso no copia, palabra por palabra, los textos constitucionales del periodo. Lo que hace es adaptar el llamado esta-

71 El artículo 25 dispone, además, que Toda Ley para levantar Rentas tendrá su origen en la Sala de Representantes; pero el senado concurrirá con sus reparos como en otra cualquiera ley. $A A, \mathrm{~T} .12$.

$72 A A$, T. 12.

$73 A A$, T. 12. 
do federal a las condiciones existentes en el Río de la Plata. Señalo algunos ejemplos. El vocablo provincia es el predominante y no el de estado para referirse a una unidad territorial soberana, esto también lo vimos en los otros usos de federalismo. Es el caso de Mariano Moreno, cuando analiza la noción de federalismo en las páginas de La Gaceta en el año 1810. En Venezuela se usan indistintamente uno u otro, y en Estados Unidos se emplea el de estado. La religión debe ser la católica, como figura frecuentemente en otros proyectos constitucionales rioplatenses. En Estados Unidos no se especifica ninguna en especial, permitiendo que cada ciudadano practique la fe que desee.

No se usa, además, la noción de Cámara de Representantes como en Estados Unidos y Venezuela, sino la de Sala. Utiliza otros años de duración del mandato de los senadores, en la de Cardoso son dos o tres años, con renovación de sus miembros cada año; en la de Estados Unidos son seis años y su renovación cada dos. Por otra parte, no hay elección sino sorteo. Los cambios en los años de duración de los senadores responde a un espíritu de equilibrio y límite del poder, que lo vemos durante toda la década, especialmente lo hemos percibido en los grupos políticos ubicados en la oposición, como El Censor hacia 1816 y 1818, así también en los confederacionistas entre 1817 y 1820.

Para comprender esta forma de apropiación y reelaboración de este letrado oriental detengámonos, tan sólo un instante, en algunos aspectos propios de la llamada recepción de las ideas. Como anota con entera claridad Peter Burke, tanto los historiadores como los especialistas en temas literarios han puesto en duda la dicotomía entre «producción» y «consumo cultural», señalando el modo en que todos nosotros modificamos aquello que vamos a adquirir adecuándolo a nuestras necesidades ${ }^{74}$. Es más útil dejar de poner el foco de nuestra atención en aquello que es asimilado o bien preguntar no por quién, e indagar, por el contrario, el proceso mediante el cual se produce esta absorción, recreación, domesticación y transformación. Esta versión de la recepción remite a lo que se ha denominado «teoría de la recepción», esto es, la iniciativa de algunos investigadores de sustituir la noción de la mera «influencia» por la noción más sutil de un proceso de adaptación creativa.

En esta línea, resulta conveniente retomar la lógica interpretativa de H. G. Gadamer, uno de sus exponentes más lucidos y reconocidos. Según su clásico trabajo sobre este tema, la relación entre texto y lector obedece a la lógica de pregunta y respuesta ${ }^{75}$. El texto es, pues, la respuesta a una pregunta; dicho de

74 Burke, 1999: 50-51.

75 Esta línea puede verse, por ejemplo, en un estudio de una sus figuras salientes: Gadamer: 1977. Una visión muy interesante sobre el estado actual de la problemática de la recepción puede consultarse en VV.AA., 1987. 
otra manera, sólo percibo en un texto aquello que tiene algo que ver conmigo. Lo que me importa, lo que me interesa y está en línea con mis intereses, ideas y valores. Lo cierto, en ese marco de verdadera reflexión política, es que la respuesta que el texto da a mi pregunta nunca es plenamente suficiente, de manera que el propio texto plantea también preguntas, y es ahora al lector al que le toca encontrarlas. ¿Cuáles son algunas de las preguntas que Cardoso hace al modelo de estado federal (ya que ese texto no se asimila a su paisaje político) y cuáles son sus respuestas? Bien podría decirse, utilizando casi las palabras de Gadamer, que Cardoso lee en la constitución de Estados Unidos aquello que tiene que ver con él, es decir, para poner un ejemplo claro, con la respuesta pretende imponer, un poder central, respeto a los derechos de las provincias, pero esto no es del todo suficiente, así éste plantea sus preguntas, sus preocupaciones, aquello que debe adaptar a su propia constitución, por ejemplo un tópico indiscutible: la vigencia e imposición de una sola religión, la católica. Como se sabe, en el modelo de estado federal no se presenta la materia religiosa en esos términos, de ahí la modificación, la adaptación que hace nuestro escritor a la propia realidad local, a sus propios intereses.

\section{II.1.3. Fragmentos para armar. Artiguistas en Buenos Aires. A modo de conclusión.}

1. ¿Qué puede decirse acerca del material federalista? Hacia 1812, las iniciativas políticas llevadas adelante en la ciudad de Buenos Aires por Cardoso como un miembro de la oposición coincide a grandes rasgos con las líneas trazadas en las instrucciones de abril, que, un año más tarde, como diputado de esa tendencia, recibe como mandato. En ambos momentos sobresalen dos motivos ideológicos: la independencia absoluta y la instauración de un sistema confederal fijado en las páginas de una carta constitucional. No es verdad, entonces, que en este último tramo de la experiencia artiguista, «aunque se hable permanentemente de Confederación, como sostiene Carlos Segreti, lo que se intenta estructurar es un Estado Federal donde las partes integrantes conserven una gran autonomía» ${ }^{76}$.

Es claro que el concepto político de estado federal no surge en las páginas de las Instrucciones. Sin embargo, sí emerge en el llamado proyecto federal encontrado en su domicilio y redactado por él. En este caso, no estoy de acuerdo con Alberto Demicheli cuando plantea que tal proyecto federal es «plenamente confirmatorio de las Instrucciones orientales $\rangle^{77}$ (confederación), en

76 Segreti, 1980: 41.

77 Demicheli, 1962: 43. 
cuanto se trata de una especie de paso previo a una organización nacional de tipo federalista. Para el especialista del artiguismo, ambos modelos, la confederación planteada en las Instrucciones y el estado federal expuesto en el Proyecto federal, no son del todo contradictorios, en la medida que uno es un escalón necesario y obligatorio para llegar al otro. A sus ojos, se trata de un mismo plan, de un feliz viaje ascendente por las variadas formas de poder de ese signo ideológico.

Mi punto de vista es diferente, ambos planteos federales no son sólo distintos, sino que además son opuestos y excluyentes. En la experiencia norteamericana, aquéllos que proponen el estado federal rechazan de plano la confederación, porque resulta un sistema político débil para enfrentar la crisis política emergente en la lucha colonial ${ }^{78}$. El primero (es bueno insistir en ello) deposita todo el poder en la nación y sólo delega en los estados provinciales miembros aquellas atribuciones que no atentan con el buen funcionamiento nacional. En este sentido, como ha señalado Natalio Botana, se trata de «un pacto político entre estados que renuncian a una parte de su soberanía» $\rangle^{79}$. Es opuesto, por consiguiente, a la confederación, debido a que las provincias ceden muy pocas atribuciones al poder central, y es precisamente de este modo que de hecho pone ese proyecto al revés, cabeza abajo. El poder nacional es débil aquí porque los atributos más sobresalientes corresponden a los estados provinciales, impuestos, ejércitos, acuñación de moneda, etc. Se trata, en rigor, de dos proyectos distintos de Estado y de nación.

Pues bien, ¿por qué tienen dos versiones diferentes de planes federalistas? ¿Qué tipo de respuesta política se pretende dar con una constitución que adopta la forma de un estado federal? Bien podría conjeturarse que la idea que presentan sobre la mesa política los artiguistas es la de confederación o alianza. Es lo que vimos anteriormente. Esa idea responde al clima de cuestionamiento que rodea al poder, expresa, nítidamente, las quejas y los reclamos de los pueblos, quienes desean retomar su libertad y soberanía local frente a la tendencia de subordinación de Buenos Aires. Es probable que esta segunda constitución federalista haya sido pensada como una alternativa en una instancia de negociación con los sectores centralistas porteños, ya que responde a las condiciones políticas de la época. Durante 1813 ya vimos cómo el gobierno de Buenos Aires da muestras contundentes que la idea que flota sobre el aire de los tiempos es la concentración del poder. Pero al mismo tiempo también se presenta un insistente reclamo de las provincias que piden que se respeten los derechos

78 Morgan, 2006. Véase tercera parte, «La vía estadounidense».

79 Botana, 2005: 95. 
de los pueblos. Es decir, existen las dos ideas en juego, por un lado la idea de concentrar el poder por el nuevo contexto europeo y la amenaza de invasión en tierra americana y, por otra, las ideas de respetar los derechos de los pueblos (su poder soberano). Esta aparente oposición de poderes encuentra una respuesta en la segunda constitución federal de Estados Unidos, en cuanto aparecen allí las soberanías, la nacional y la de los estados miembros.

2. Como suele ocurrir en el terreno de la historia, no es permitido que una noción sea valida para cualquier época, y muchas veces - como se ha llamado la atención - ni siquiera se admite que sea adecuada a todos los aspectos que pretenda designar en un periodo determinado. Por consiguiente, a fin de evitar disquisiciones abstractas (o falsas discusiones), para intentar definir a los artiguistas de Buenos Aires es preciso indagar tres nociones históricas: la de simpatizante, la de activista y la de partido ${ }^{80}$.

La noción de simpatizante alude a la idea de individuos que pueden mostrarse atraídos por las creencias o el accionar de un caudillo. Se trata de sujetos que pueden opinar a su favor, o es posible que participen ocasionalmente de algún acto que lo favorezca. Sin embargo, no tienen un grado de compromiso con él, ni una tarea política concreta. La perspectiva del activista es diferente. Es la de alguien que sí tiene una tarea política concreta y que responde a los mandatos de ese jefe. Puede participar de un Movimiento de Pueblo, redactar o distribuir pasquines, informar a sus superiores sobre el clima político que generalmente rodea los pasos oficiales y de los de la llamada oposición. La concepción de partido antiguo, como los que se presentan en esta época, es la de grupos poco uniformes si se los comparan con los partidos modernos de fines de siglo XIX argentino o los de la segunda mitad de ese siglo en Europa. Son segmentos políticos que generalmente siguen a un líder, poseen una mínima estructura organizativa, contactos aceitados entre sus miembros, y partidarios dispuestos a sostenerlo. No son simples simpatizantes, ni activistas individuales, sino que pueden reunir un grupo de miembros en una tarea conjunta.

¿Simpatizantes, activistas o partido artiguista? No son sólo simpatizantes, ya que como se ha visto sostienen una tarea política en Buenos Aires. Tampoco constituyen un partido organizado, no tienen una estructura organizativa visible, ni hemos observado que se muevan en grupos numerosos. Es probable que sean activistas que participan como agentes o consejeros de José Artigas. Reúnen las características señaladas en los activistas.

En resumen, los artiguistas mantienen contactos públicos con autoridades de primer orden del gobierno de Buenos Aires, además, disponen en su agenda

80 Todd, 2000. 
política de diversas cartas constitucionales y proyectos sobre la independencia; y, es muy probable que hayan tenido, asimismo, adherentes entre los principales vecinos de la ciudad. Esos partidarios les cuentan a su jefe qué pasa en Buenos Aires: distintos movimientos de tropas y acciones políticas, sus reuniones con los miembros del gobierno, etc. Participan, además, en la política local: Movimientos de Pueblo, en la plaza, en los diarios, en el club morenista.

La trayectoria pública de Cardoso en Buenos Aires revela, por ejemplo, que tiene una larga participación pública en esa ciudad y que mantiene contactos con los sectores de poder político. En cuanto a los posibles contactos que pudieron mantener Cardoso y el grupo morenista bien podría decirse que existieron y que ellos ocurrieron en momentos políticos de significación. En primer lugar, durante las protestas de abril de 1811 compartieron el descontento por lo que allí sucedía. Esos días los encontraron, por lo menos, en la misma corriente de opinión. En segundo lugar, los contactos parecen ser más estrechos en las sesiones de la Sociedad Patriótica. Con ese grupo coincidieron en la necesidad de imponer una constitución y en la declaración inmediata de la independencia, $\mathrm{y}$, en la apelación positiva a las bondades que proporcionaría el establecimiento de un sistema federal. En tercer lugar, durante la Revolución de octubre de 1812, integra el grupo de civiles que firma la Representación que se redacta en la Playa de Mayo, representación que firma en primer término Monteagudo como líder de los grupos que allí están congregados. Todos estos indicios señalarían la posibilidad de que hayan tenido algún tipo de vínculo. Pero si ello forma parte del orden de lo probable, sí, en cambio, es factible afirmar que compartieron por lo menos en esos tres instantes mencionados un campo común de creencias.

\section{BIBLIOGRAFÍA}

Canter, Juan, «La Revolución de abril de 1815 y la organización del nuevo directorio», Ricardo Levene, Historia de la Nación Argentina, vol. VI, S/F.

Comisión Nacional «Archivo Artigas», Archivo Artigas, Montevideo, Monteverde, 1987.

Corominas, J., Breve diccionario etimológico de la lengua castellana, tercera edición muy revisada y mejorada, editorial Gredos, Madrid, 1987.

Baczko, Bronislaw, Los imaginarios sociales. Memorias y esperanzas colectivas, Buenos Aires, 1991.

Bobbio, Norberto y Matteuci, Nicola, Diccionario de política, Siglo XXI, 1985. 
Botana, Natalio, La tradición republicana. Alberdi, Sarmiento y las ideas políticas de su tiempo, Buenos Aires, 2005.

Burke, Peter, El Renacimiento, Barcelona 1999.

Burke, Peter, Hablar y callar. Funciones sociales del lenguaje a través de la historia, Barcelona, 1996.

De la Torre, Nelson; Rodríguez, Julio C. y Sala de Touron, Lucia, La Revolución agraria artiguista (1815-1816), Montevideo, Ediciones Pueblos Unidos, 1969.

Frega, Ana, Pueblos y soberanía en la revolución artiguista. La región de Santo Domingo Soriano desde fines de la colonia a la ocupación portuguesa, Ediciones de la Banda Oriental, 2007.

Demicheli, Alberto, Origen federal argentino, Depalma, Buenos Aires, 1962.

Gadamer, H. G., Verdad y método, Salamanca, Ed. Sígueme, 1977.

García, Flavio, El «ciudadano» Felipe Cardoso», Museo, Dirección General de Extensión Universitaria, división de publicación y ediciones, Montevideo, 1980.

Guerra, Francois-Xavier; Lemperierer, Annick et al., Los espacios públicos en Iberoamérica. Ambigüedades y problemas, Siglos XVIII-XIX, México, 1998.

González Bernaldo, Pilar, «La Revolución Francesa y la emergencia de nuevas prácticas de la política en el Río de la Plata revolucionario (1810-1815)», Boletín del Instituto de Historia Argentina y Americana Dr. Emilio Ravignani, tercera serie, $1{ }^{\text {er }}$ semestre de 1991.

Mascareños, Carlos, Nueva Enciclopedia Jurídica, tomo IV, Barcelona, 1952.

Matteucci, Nicola, Organización del poder y libertad. Historia del constitucionalismo moderno, Editorial Trotta, 1998.

Montesquieu, Del espíritu de las leyes, Tomo I, Hyspamérica, 1984.

Morgan, Edmund S., La invención del pueblo. El surgimiento de la soberanía popular en Inglaterra y Estados Unidos, Buenos Aires, 2006.

Halperin Donghi, Tulio, Revolución y guerra. Formación de una elite dirigente en la argentina criolla, Buenos Aires, 1979.

Herrero, Fabián, Movimientos de Pueblo. La política en Buenos Aires luego de 1810, Buenos Aires, 2007.

Herrero, Fabián, Federalistas de Buenos Aires. Sobre los orígenes de la política revolucionaria, 2008 (inédito).

Ibarguren, Carlos (hijo), «Genealogía, hombre de Mayo», Revista del Instituto Argentino de Ciencias Genealógicas, Buenos Aires, 1961.

Reyes Abadie, Washington, Artigas y el federalismo en el Río de la Plata, 1810-1820, Ediciones de la Banda Oriental, 1994. 
Reyes Abadie, Washington; Bruschera, Oscar H. y Melogno, Tabare, Documentos de Historia Nacional y Americana. El ciclo Artiguista, Tomo I, Montevideo, 19681969.

Segreti, Carlos, La aurora de la independencia, 1810-1815, Buenos Aires, 1980, tomo 2.

Souto, Nora, «Unidad/federación», Noemi Goldman, Lenguaje y revolución. Conceptos políticos clave en el Río de la Plata, 1780-1850, Promteo, 2008, Buenos Aires.

Street, John, Artigas y la emancipación del Uruguay, Barreiro y Ramos, S.A., 1967, Montevideo.

Todd, Allan, Las revoluciones, 1789-1917, Madrid, Alianza, 2000.

VV.AA., Estética de la recepción, compilación de José Antonio Mayoral, Arco-libros, 1987.

Verdo, Genevieve, L'indepéndance argentine entre cités et nation (1808-1821), París, Publicacions De La Sorbonne, 2006.

Verdo, Genevieve, «¿Soberanía del pueblo o de los pueblos? La doble cara de la soberanía durante la revolución de la independencia (1810-1829)», Andes, n. ${ }^{\circ}$ 13, CEPIHA, Salta, 2002.

Fecha de recepción: 11 de noviembre de 2008

Fecha de aceptación: 27 de enero de 2010

\section{FRAGMENTS FOR PIECING TOGETHER. SIGNS OF THE ARTIGUIST PRESENCE IN BUENOS AIRES}

This study introduces signs of the presence of Artiguist agents operating in the Buenos Aires political scene during the decade of the 1810s. Based on documents contained in the Artigas Archive, local press entities and governmental files from the General Archive of the Nation, it is possible to trace some of their activities and identify some of their political plans. Together, this evidence calls into question the strong image provided by federal historiography, which holds that there were no Artiguist ideas in the province during the early revolutionary war years.

KeY words: Federalism, Artiguist movement, politics, revolution, Buenos Aires. 